\title{
Amplitude of the rabbit's unconditioned nictitating membrane response in the presence of a conditioned inhibitor
}

\author{
JOHN E. DESMOND, ANTHONY G. ROMANO, and JOHN W. MOORE \\ University of Massachusetts, Amherst, Massachusetts 01003
}

\begin{abstract}
Using a light or backshock as the reinforced CS (A) and a tone or backshock as the conditioned inhibitor (X), rabbits experienced conditioned inhibition training in an A+/AX- paradigm. Following training, the amplitude of the unconditioned nictitating membrane response elicited by a mild (.5-mA) paraorbital shock was measured in the presence of $\mathrm{X}$ and $\mathrm{AX}$ and expressed as a percentage of the amplitude of the UR to the shock presented alone. In Experiment 1, the effect of $\mathrm{X}$ and $\mathrm{AX}$ on UR amplitude for conditioned inhibition animals was compared with that of control animals treated to a variety of pretest procedures. In general, UR amplitude in the presence of $X$ exceeded that observed to the US presented alone. There was no consistent difference between the experimental and control groups. In Experiments 2-5, A test trials were added as an alternative reference point. Again, UR amplitude increased rather than decreased UR amplitude. In addition, $X$ as a conditioned inhibitor enhanced the facilitating effect of A on UR amplitude in four out of five experiments. These findings have implications for theories of the "locus of action" of conditioned inhibitors.
\end{abstract}

According to Wagner and Rescorla (1972), conditioned inhibition training $(\mathrm{A}+/ \mathrm{AX}-)$, where reinforcement is administered on A trials and withheld on AX trials, results in the acquisition of positive associative strength to stimulus $\mathrm{A}$ and negative associative strength to $X$. The positive associative strength of $A$ is indicated by its ability to evoke CRs, while the negative strength of $\mathrm{X}$ is reflected by its ability to reduce or suppress CRs when compounded with $A$. Thus, $\mathbf{A}$ is typically referred to as a conditioned excitor and $\mathrm{X}$ a conditioned inhibitor.

One commonly accepted view of conditioning assumes that a stimulus that has been repeatedly paired with a US, such as A, becomes capable of evoking CRs by developing an excitatory association with an internal representation or memory of the US (Rescorla, $1974,1979)$. With this view in mind, Rescorla and Holland (1977) have delineated four potential loci for the action of a conditioned inhibitor, $X$. First, $X$ may act at the peripheral response level by preventing the exhibition of the CR evoked by A. Second, $X$ may develop an inhibitory association with $A$, thus neutralizing the excitatory strength of A. Third, the inhibitor may act on the excitatory association existing between $A$ and the internal representation of the

This research was supported by NSF Grant BNS 77-14871 to the third author. The authors appreciate the contributions of Professors J. Ayres and R. Clifton in all phases of this research. Anthony G. Romano is presently at Ohio University, Athens, Ohio. Requests for reprints should be sent to John W. Moore, Middlesex House, Department of Psychology, University of Massachusetts, Amherst, Massachusetts 01003.
US. Finally, the view favored by Konorski (1948) and Rescorla $(1974,1979)$ is that X acts on the internal representation of the US by raising its threshold for activation.

Although Konorski (1948) and Rescorla $(1974,1979)$ have similar models of excitatory conditioning, they differ in one important respect. According to Konorski, a conditioned excitor evokes a CR by weakly activating a "US center" which the US itself activates more strongly. Conversely, a conditioned inhibitor prevents the execution of a CR by raising the threshold of excitability in the US center. For Rescorla, the US representation controls only conditioned responding, while, for Konorski, the US center controls both conditioned and unconditioned responding. Thus, with regard to conditioned inhibition, both views call for attenuation of conditioned responding in the presence of a conditioned inhibitor while only Konorski's view predicts a concomitant attenuation of unconditioned responding.

Supporting Konorski's hypothesis are studies demonstrating (a) that the threshold of a motor reaction in dogs elicited by electrical brain stimulation (ESB) is higher in the presence of a conditioned inhibitor than in the presence of either a conditioned excitor or no priming stimulus (Wagner, Thomas, $\&$ Norton, 1967), and (b) elevation of the threshold of hypothalamically elicited fear or rage in cats (Thomas \& Basbaum, 1972). Since these studies involved ESB-elicited reactions, it is not clear whether the conditioned inhibitor was, in fact, acting on the neural substrate of the UR or on US representations responsible for conditioned forms of these behaviors. 


\section{EXPERIMENT 1}

Experiment 1 was designed to determine the locus of action of a conditioned inhibitor by examining the effects of a conditioned inhibitor on UR excitability. Briefly, the design of Experiment 1 involved training under the A+/AX - paradigm followed by evaluation of UR amplitude, where the UR was elicited on the following trial types: $\mathrm{AX}, \mathrm{X}$, and US alone. Attenuation of the UR on AX trials would provide support for those views of conditioned inhibition which demand the presence of an excitatory association in order for a conditioned inhibitor to exert its effect. Alternatively, attenuation of the UR on X trials relative to US-alone trials would provide support for Konorski's (1948) proposal that conditioned inhibitors act by raising the threshold of excitability in a US center which controls both conditioned and unconditioned responding.

\section{Method}

Subjects and Apparatus. The subjects were 28 experimentally naive albino rabbits that weighed approximately $2.2 \mathrm{~kg}$. The apparatus was the same as that described in previous published reports (e.g., Marchant, Mis, \& Moore, 1972; Marchant \& Moore, 1974).

For all conditions, the excitatory CS (A) consisted of the onset of two $4.5-\mathrm{V}$ incandescent lights, while the inhibitory compound (AX) consisted of the light CS (A) in conjunction with a $1,200-\mathrm{Hz}$, 90-dB (re: $20 \mu \mathrm{N} / \mathrm{m}^{2}$ ) tone (X). During acquisition and conditioned inhibition training, the US was a $2-\mathrm{mA}$ ac shock of $50 \mathrm{msec}$ duration delivered via two stainless steel wound clip (Clay-Adams, $9 \mathrm{~mm}$ ) electrodes affixed to the skin of the intraorbital region of the right eye. The CS-US (ISI) interval was $450 \mathrm{msec}$, and the CS and US terminated together.

Procedure. Twelve animals were selected randomly for conditioned inhibition (CS) training and four were assigned randomly to each of four control groups. Following suturing of the nictitating membrane, all animals were habituated to the apparatus for a period of 50 min. Stage 1 acquisition training began 24 h later. All animals received $100 \mathrm{~A}+$ conditioning trials daily at a $30-\mathrm{sec}$ intertrial interval (ITI) until a criterion of $90 \%$ CRs in one conditioning session was achieved. Stage 2 training began on the next day and continued for a period of 14 days. In this stage, Group $\mathrm{Cl}$ received $C l$ training daily with 20 reinforced $A$ trials $(A+)$ interspersed in a random order with 20 nonreinforced $A X$ trials ( $A X-$ ) at a 30 -sec ITl. A discrimination criterion was established for Group $\mathrm{Cl}$ such that the percentage of CRs occurring to $\mathrm{AX}$ had to be at least $70 \%$ less than the percentage of CRs occurring to $A$ on at least 2 consecutive days. Since four animals did not meet this criterion, their data were not entered into any of the analyses.

Group LI $(n=4)$ received nonreinforced presentations of $X$ in Stage 2 as a control for the effects of a latent inhibitor on UR excitability. The number and distribution of $\mathbf{X}$ presentations paralleled the number and distribution of AX presentations in the experimental group. Although latent inhibitors do not suppress conditioned responding when compounded with an excitalory CS (Reiss \& Wagner, 1972), it was conceivable that nonreinforced presentations of a tone might have a nonspecific effect on UR excitability which would obscure the effects of a tone on the UR when that tone had been nonreinforced in a conditioned inhibition paradigm.

Group US $(n=4)$ received only US presentations in Stage 2, as a control for US habituation. The number and distribution of US trials in Group US paralleled the number and distribution of reinforced trials in the experimental group.
Group SD $(n=4)$ received simple discrimination training in Stage 2 with reinforced $A$ trials and 20 nonreinforced $X$ trials according to the same trials distribution parameters as for GroupCl. Moore (Note 1) reported that such a procedure does not endow $X$ with conditioned inhibitory properties unless $A$ and $X$ are in the same modality. Thus, Group SD served as a control for any interaction between reinforced presentations of $\mathrm{A}$ and nonreinforced presentations of $X$, the tone.

Finally, Group SIT $(n=4)$ was naive with respect to Stage 2 training but spent the same amount of time in the conditioning apparatus as the other groups.

Stage 3 was a testing phase in which the UR was elicited and measured on AX, X, and US-alone trials. Each trial was presented five times in an unsystematic order. Although Stage 1 and Stage 2 training employed a 2-mA US, the intensity of the US was decreased to $.5 \mathrm{~mA}$ for Stage 3 in order to avoid any ceiling effects on the amplitude of the UR and to prevent rapid conditioning. The ISI and ITI were the same as during training.

\section{Results and Discussion}

The eight animals of Group CI that attained the criterion of a $70 \%$ differential between CRs to A+ and $\mathrm{AX}$ - trials responded above the $90 \%$ level to A + for the 14 days of training and below $10 \%$ to AX - for Days 13-14. Averaged over the 14 sessions, the difference in percentage $\mathrm{CRs}$ to $\mathrm{A}+$ vs. $\mathrm{AX}-$ was highly significant $[t(7)=9.85, \mathrm{p}<.001]$.

The mean amplitude of the UR among the 24 animals tested in Stage 3 ranged from 1 to over $20 \mathrm{~mm}$ of pen movement, with an overall mean of $6.6 \mathrm{~mm}$. Neither analysis of variance nor a variety of ad hoc statistical comparisons revealed significant differences among groups in absolute UR amplitude to X, AX, or US-alone trials. More sensitive contrasts were possible when, for each animal, the mean UR amplitude on $\mathrm{X}$ and $\mathrm{AX}$ test trials was expressed as a percentage of the mean UR amplitude to the .5-mA US presented alone. These are the data of primary interest, and the relevant means for each group are shown in Table 1.

Table 1 indicates that, on the average, the amplitude of the UR was greater on X trials than on US-alone trials. With the exception of Group US, which showed no change, the percentage increase was $24 \%$ in Group CI, 9\% in Group SD, $11 \%$ in Group LI, and $21 \%$ in Group SIT. In all, 19 of the 24 animals showed a greater average UR amplitude on $X$ trials than on US-alone trials (two-tailed sign test, $p=.006$ ).

The only point at which the relative amplitude of the UR to $\mathrm{X}$ in Group $\mathrm{CI}$ appeared to be below a control comparison was in the contrast with Group LI

Table 1

Mean Amplitude of URs on $X$ and AX Trials as a Percentage of US Alone

\begin{tabular}{cccccc}
\hline & \multicolumn{5}{c}{ Group } \\
$\begin{array}{ccccc}\text { Test Trial } \\
\text { Type }\end{array}$ & CI & SD & LI & US & SIT \\
\hline X & 124 & 109 & 210 & 100 & 121 \\
AX & 248 & 104 & 211 & 103 & 106 \\
\hline
\end{tabular}


$(124 \%$ vs. $211 \%)$. However, when considered with the data of the other control groups, there is little evidence to support the idea that a conditioned inhibitor raised the threshold of UR excitability, thereby attenuating the UR. One-tailed Mann-Whitney $\mathrm{U}$ tests indicated that the amount of tone facilitation exhibited by Group CI did not differ from that exhibited by Group SD (U = 12, p = .285), Group LI $(\mathrm{U}=6, \mathrm{p}=.055)$, Group US $(\mathrm{U}=11, \mathrm{p}=.23)$, or Group SIT (U = 16, $p=.533)$.

One interesting facet of the data depicted in Table 1 is the experimental group's response to the AX compound. It appears as though the presence of the conditioned inhibitor amplified this group's response to the compound relative to the other groups. In order to determine the magnitude of this enhancement of the UR produced by combining $\mathrm{A}$ and $\mathrm{X}$, a difference score was computed for each animal by subtracting its relative mean UR amplitude on $X$ trials from its mean relative UR amplitude on AX trials. These difference scores were subjected to a one-way Kruskal-Wallis analysis of variance, which indicated a significant difference among the groups $[\mathrm{H}(4)=12.03, \mathrm{p}<.02]$. In light of this difference, individual Mann-Whitney $U$ tests (twotailed) were conducted on the difference scores in order to compare the experimental group with each of the control groups. Group $\mathrm{CI}$ was found to be significantly different from GroupSD ( $U=4, p=.048)$, Group US $(\mathrm{U}=2, \mathrm{p}=.016)$, and Group SIT $(\mathrm{U}=0, \mathrm{p}=.004)$. However, the difference between Group $C I$ and Group LI was not significant $(\mathrm{U}=6, \mathrm{p}=.110)$.

The failure to find a significant difference in the enhancement effect (AX-X) between Groups $\mathrm{CI}$ and LI suggests that it arose as a nonspecific effect of nonreinforced tone presentations during Stage 2 rather than as a specific effect of conditioned inhibition training, but if this were so, the effect should also have appeared in Group SD. Nevertheless, the observation that UR excitability was further increased above $100 \%$ when $\mathrm{A}$ was compounded with $\mathrm{X}$ in Group CI rules out the possibility that the conditioned inhibitor, while failing to reduce UR excitability when presented alone, might lower UR excitability in the presence of the conditioned excitor on which it was based.

\section{EXPERIMENT 2}

Experiment 1 failed to demonstrate any attenuation of UR amplitude in the presence of $X$, when the inhibitor was presented either alone or in compound with A, the excitatory CS. Instead, the evidence suggested that the tone employed as the conditioned inhibitor actually enhanced UR amplitude. Comparisons with a variety of control groups also failed to indicate a reduction of UR amplitude in the presence of $\mathrm{X}$.
Experiment 2 sought further evidence on the question of UR attenuation in the presence of a conditioned inhibitor by introducing $\mathrm{A}$ trials in addition to $\mathrm{X}, \mathrm{AS}$, and US-alone trials during the test phase. The A test trials provide an alternative reference point against which any attenuation of UR amplitude in the presence of $X$ might be detected. In addition, Experiment 2 entailed a number of departures from the training and testing procedures employed in Experiment 1, the principal one being the use of a tactile stimulus (backshock) instead of light as stimulus A.

\section{Method}

Subjects and Apparatus. The subjects were eight experimentally naive rabbits like those employed in Experiment 1 . The excitatory $\mathrm{CS}$ (A) consisted of $60-\mathrm{Hz}$ ac electrical stimulation of $7 \mathrm{~V}$ delivered across safety-pin electrodes implanted subcutaneously on the animal's back, one on each side of the spine in the thoracic region and approximately 2 in. apart. The conditioned inhibitor (X) and the US were the same as in Experiment 1.

Procedure. All animals received an initial sequence of four daily acquisition sessions consisting of 100 reinforced trials at a constant ITI of $15 \mathrm{sec}, 50$ to $A$ and 50 to $X$ in a random order. This was followed by 17-21 daily sessions of $\mathrm{CI}$ training consisting of $50 \mathrm{~A}+$ trials and $50 \mathrm{AX}$ - trials in a random order, with a constant ITI of $15 \mathrm{sec}$. On the day following CI training, the US was decreased to $.5 \mathrm{~mA}$, as in Experiment 1, and each animal received 12 test trials of each of the following type, in a random order: A, X, AX, and US alone. The ISI was $500 \mathrm{msec}$, the ITI was $30 \mathrm{sec}$, and UR amplitude to the .5-mA shock was measured on each trial.

\section{Results and Discussion}

Seven of the eight animals attained a criterion of differential responding of greater than $90 \%$ CRs to $\mathrm{CS}+$ and less than $40 \%$ CRs to CS - by the 12 th session of $\mathrm{CI}$ training (range: 10-19). The eighth animal (D4) failed to completely suppress CRs to CS- , but showed a reliable amplitude differentiation between CS + and CS - by the end of training.

Table 2 (left-hand portion) summarizes the test data for each animal. Each entry consists of the mean UR amplitude on the 12 test trials to that stimulus divided by the mean UR amplitude on the 12 US-

Table 2

Mean Amplitude of URs on X, A, and AX Trials as a Percentage of US Alone

\begin{tabular}{lrrrrrrr}
\hline & \multicolumn{3}{c}{ Experiment 2 } & & \multicolumn{3}{c}{ Experiment 3 } \\
\cline { 2 - 4 } \cline { 6 - 7 } Animal & \multicolumn{1}{c}{ X } & A & AX & & X & A & AX \\
\hline D1 & 103 & 147 & 204 & & 127 & 105 & 115 \\
D2 & 87 & 112 & 108 & & 117 & 104 & 111 \\
D3 & 215 & 176 & 203 & & 105 & 101 & 101 \\
D4 & 114 & 111 & 187 & & 109 & 150 & 143 \\
D5 & 212 & 134 & 211 & & 166 & 92 & 208 \\
D6 & 113 & 108 & 120 & & 107 & 110 & 130 \\
D7 & 90 & 153 & 171 & & 126 & 117 & 121 \\
D8 & 141 & 91 & 112 & & 113 & 108 & 113 \\
Mean & 134 & 129 & 164.5 & 121 & 111 & 130 \\
\hline
\end{tabular}


alone trials. Entries have been multiplied by 100 in order to eliminate decimals.

Six of the eight animals showed an enhanced UR in the presence of $X$, the conditioned inhibitor. The average increase across all animals was $34 \%, 5 \%$ greater than the average effect of A on UR amplitude. This difference is not statistically significant.

However, the enhancement of UR amplitude by the AX compound, averaging $64.5 \%$, is significantly different from UR amplitude in the presence of $A$ (one-tailed sign test, $\mathrm{p}=.035$ ). This observation confirms the observations from Experiment 1 which suggested that the conditioned inhibitor potentiated the facilitating effect of the conditioned excitor on UR excitability.

Nevertheless, the important point from the standpoint of the essential purpose of this investigation is that $X$ did not attenuate UR amplitude, either in relation to US-alone test trials or in relation to $\mathrm{A}$ test trials.

\section{EXPERIMENT 3}

The results of Experiment 2 are consistent with those of Experiment 1, but CI training and test procedures differed in the two experiments, the principal differences being substitution of backshock for light in the role of stimulus $\mathrm{A}$ and the introduction of $\mathrm{A}$ test trials. Experiment 3 sought evidence on the effect of X on UR amplitude relative to A test trials in which $A$ was a light.

\section{Method}

The subjects were the same as those employed in Experiment 2. Conditioned inhibition training employed the same apparatus and procedures as Experiment 2 except that the illumination of the two panel lights (see Experiment 1) served as stimulus A. Conditioned inhibition consisted of 14 daily sessions of 100 trials (50 A+ and $50 \mathrm{AX}-)$ at an ITI of $15 \mathrm{sec}$.

Testing consisted of a single 48-trial session during which 12 each $\mathrm{A}, \mathrm{AX}, \mathrm{X}$, and US-alone test trials were presented in a ran. dom order at an ITI of $30 \mathrm{sec}$. As in Experiments 1 and 2, the current level of the US was decreased from 2 to $.5 \mathrm{~mA}$ in order to avoid ceiling effects.

\section{Results and Discussion}

On the average, the eight animals gave better than 99\% CRs on A+ trials and $37 \%$ on $\mathrm{AX}$ - trials during training. Table 2 (right-hand portion) presents the mean UR amplitude to A, X, and AX test trials as a percentage of US alone.

As in Experiments 1 and 2, $\mathrm{X}$ produced an increase rather than a decrease in UR amplitude, averaging $21 \%$ in this particular instance and with all eight animals showing the effect (one-tailed sign test, $\mathrm{p}=$ .004). Also consistent with Experiment 2, there was no marked difference between UR amplitude on A and $X$ trials, but once again the addition of $X$ to $A$ produced a statistically significant enhancement by increasing UR amplitude from $111 \%$ to $130 \%$ on the average (one-tailed sign test, $\mathrm{p}=.035$ ).

\section{EXPERIMENT 4}

In the previous experiments, the effect of the conditioned inhibitor $(X)$ on UR excitability during the test phase was ascertained using the ISI employed during CI training, i.e., 450 or $500 \mathrm{msec}$. Since $\mathrm{X}$, by definition, suppresses CRs to the excitatory stimulus (A) over the period of time that precedes the US, that is, the ISI, it is possible that any suppressive effect of $X$ on the UR would also appear within this interval. Experiment 4, employed a 500-msec ISI during $\mathrm{CI}$ training, but this was shortened to 250 or $350 \mathrm{msec}$ during the test so that the UR to the weak US might be evoked at a point in time when $X$ normally suppresses responding. The other major departure from the previous experiments was the use of $\mathrm{CI}$ "warm-up" trials immediately prior to the test phase.

\section{Method}

Training. As in Experiment 2, naive rabbits $(n=7)$ were initially conditioned to A (onset of panel light, as in Experiments 1 and 3 ) and $X$ (the tone, as described in Experiment 1). Three rabbits then received 26100 -trial sessions of $\mathrm{A}+/ \mathrm{AX}$ - training, two sessions per day. Four rabbits received 13 200-trial sessions of $\mathrm{Cl}$ training, one session per day. The ITI was constant at $15 \mathrm{sec}$, the ISI equaled $500 \mathrm{msec}$, and the physical aspects of all stimuli were as described in Experiment 1.

Testing. On the test day, the animals accustomed to 100-trial sessions received $50 \mathrm{~A}+$ and $50 \mathrm{AX}$ - trials in a random sequence as a CI "warm-up." This was followed immediately by the 48 trial test series that included $12 \mathrm{~A}, \mathrm{X}, \mathrm{AX}$, and US-alone trials in random series, at a constant ITI of $30 \mathrm{sec}$, exactly as described in Experiment 2. Although the intensity of the US was reduced from 2 to $.5 \mathrm{~mA}$, as in the other experiments, the ISI was halved to $250 \mathrm{msec}$. The other four animals, accustomed to 200-trial sessions, received a 100-trial CI "warm-up," followed immediately by the 48-trial test series described above, except that the ISI was reduced from 500 to $350 \mathrm{msec}$ instead of $250 \mathrm{msec}$.

\section{Results and Discussion}

All seven subjects achieved stable patterns of $\mathrm{CI}$ performance prior to the test session. The average percentage of CRs to A+ during the "warm-up" CI trials on the test day was $96 \%$, and the average percentage of CRs to $\mathrm{AX}$ - trials was $43 \%$.

Since the pattern of UR amplitudes on the various types of test trials was the same for the two subgroups, that is, those accustomed to 100 - and 200 trial sessions, respectively, the pooled results are summarized as follows: (1) UR amplitudes in the presence of $\mathrm{X}$ averaged $110 \%$ of UR amplitudes to the US alone [estimated standard error of the mean $(\mathrm{ESM})=6.7 \% 1 ;(2)$ UR amplitudes in the presence of $A$ averaged $128 \%$ of UR amplitudes to the US alone (ESM $=9.1 \%$ ); (3) UR amplitude in the presence of AX averaged $120 \%$ of UR amplitudes to the US presented alone $(\mathrm{ESM}=7.0 \%)$.

Unlike the previous experiments, a rather high proportion of $X$ trials $(\mathbf{4 2 \%})$ contained criterion CRs as well as URs. These CRs may be attributable to the initial conditioning to $\mathrm{X}$ that occurred before $\mathrm{CI}$ training, to the "warm-up" series, or to the use of 
ISIs favorable for conditioning during the test phase (see Gormezano \& Moore, 1969). Although generally small in amplitude, averaging less than $15 \%$ of UR amplitudes on these trials, their presence might have spuriously increased UR amplitude by, for example, overcoming resting inertia. Accordingly, UR amplitudes on X trials were compared with US-alone trials using only the data from those $\mathrm{X}$ trials that did not contain CRs. The results did not change appreciably, however, as the average over the seven animals was $112 \%(\mathrm{ESM}=8.8 \%)$ compared with $110 \%$ using all the data. In both cases, five of seven subjects showed larger UR amplitudes on X trials than on US-alone trials. This falls short of statistical significance by a sign test.

Although the present experiment is consistent with the previous ones in failing to demonstrate attenuation of UR amplitude in the presence of $\mathrm{X}$ in comparison with US alone, the average percentage-ofUS-alone score was $8 \%$ lower on AX trials than on A trials. This difference, though within 1 estimated standard error, stands in contrast to the results of Experiments 2 and 3, where AX trials typically yielded higher UR amplitudes than did A trials.

\section{EXPERIMENT 5}

The previous experiments, involving a number of procedural variations, are consistent in their failure to demonstrate reductions of UR excitability following onset of a conditioned inhibitor. In the presence of a conditioned inhibitor, UR amplitudes evoked by a weak US were approximately $20 \%$ larger on the average than those evoked by the US presented alone. Experiment 4 showed that the conditioned inhibitor failed to reduce UR amplitudes (1) when the US occurred at a point in time when CRs are normally suppressed and (2) on trials not complicated by the presence of CRs, however small in magnitude.

Failure to observe a reduction of UR excitability in these experiments could have been due to the choice of a tone as the conditioned inhibitor. Therefore, the tactile stimulus (backshock) employed as the excitatory CS (A) in Experiment 2 was used as the conditioned inhibitor $(\mathrm{X})$ in Experiment 5.

\section{Method}

Four additional naive rabbits (Squad 1) received an initial series of four daily acquisition sessions consisting of 100 reinforced trials at a constant ITI of $15 \mathrm{sec}, 50$ to the onset of the two panel lights (A), as in Experiments 1 and 3, and 50 to the backshock (X), as in Experiment 3, except increased to 7.9 V. This was followed by 20 daily sessions of $\mathrm{Cl}$ training $(\mathrm{A}+/ \mathrm{AX}-)$ and one test session, in all respects identical to the procedures of Experiments 2 and 3. Four additional animals (Squad 2) received the same treatment except for the following modifications: (1) Cl Training Sessions 17-20 consisted of 200 trials instead of 100 so that these animals might become accustomed to the longer session; (2) the test phase was preceded by $100 \mathrm{Cl}$ "warm-up" trials; and (3) the ISI during the test phase was reduced from 500 to $350 \mathrm{msec}$.
}

\section{Results and Discussion}

Squad 1 gave an average of $100 \%$ CRs on $\mathrm{A}+$ trials and $55 \% \mathrm{CRs}$ on $\mathrm{AX}$ - trials the day before the test session. Squad 2 gave an average of $100 \% \mathrm{CRs}$ on $\mathrm{A}+$ trials and $21 \%$ on $\mathrm{AX}-$ on the $100 \mathrm{CI}$ "warm-up" trials immediately preceding the test phase.

The pattern of UR amplitudes to the various testtrial types was the same for both squads, and the combined results are as follows: (1) UR amplitudes on $X$ trials averaged $116 \%(119 \%$ for Squad 2$)$ of US-alone trials $(E S M=7.4 \%)$, with seven out of eight subjects showing larger UR amplitudes on $\mathrm{X}$ trials than on US-alone trials (one-tailed sign test, $\mathrm{p}=.035$ ); (2) UR amplitudes on A trials averaged $111 \%$ of US-alone trials (ESM $=14.5 \%)$; (3) UR amplitudes on AX trials averaged $119 \%$ of US-alone trials $(\mathrm{ESM}=11.1 \%)$, with seven out of eight subjects giving larger UR amplitudes on AX - trials than on A trials (one-tailed sign test, $\mathrm{p}=.035$ ); and (4) UR amplitudes on $X$ trials without $\mathrm{CRs}$ averaged $125 \%$ of US-alone trials (ESM $=8.4 \%$ ). These results are consistent with previous experiments in which $\mathrm{X}$ was a tone instead of a backshock stimulus.

\section{GENERAL DISCUSSION}

Since the conditioned inhibitors employed in this investigation did not attenuate URs elicited by a .5-mA eyeshock, the present results argue against Konorski's (1948) view that conditioned inhibitors act on a "US center" common to both CRs and URs. Instead, they provide support for Rescorla's $(1974,1979)$ position that conditioned inhibitors act on an internal representation of the US whose arousal is responsible for the CR.

Taken as a whole, the experiments reported here demonstrated a reliable tendency for conditioned inhibitors to increase UR amplitude. The extent of the increase (averaging 20\%) is within the range that might be expected on the basis of Ison and Leonard's (1971) demonstration of tone-induced facilitation of the rabbit's unconditioned NMR. An essential point is that the extent of this facilitation did not appear to be reduced by virtue of the tone's status as a conditioned inhibitor.

Other conditioned stimuli besides the tone increased UR amplitude in this investigation. For example, backshock alone (Experiment 2) increased UR amplitude an average of $29 \%$ and light alone (Experiment 3 ) increased UR amplitude by $11 \%$.

The most parsimonious explanation of the further increase of UR amplitude noted on AX test trials noted in Experiments 2, 3, and 5 is that two stimuli in combination produce a greater degree of UR enhancement than does one. The difficulty with this explanation is that it fails to account for the negligible increases in UR amplitude on $A X$ test trials 
noted in Groups SD, US, and SIT of Experiment 1. As noted in connection with that experiment, there may be something unique in $\mathrm{CI}$ training that promotes the effect. One possibility is that CI-trained animals become accustomed to $\mathrm{A}$ and $\mathrm{X}$ occurring together and that an acquired configural component contributes to UR enhancement. Another possibility is that the surprising occurrence of the US following AX- experience potentiates the UR enhancement effect. Further experimentation could resolve this issue.

Despite these unresolved questions, the present investigation indicates that conditioned inhibitors presented alone did not reduce (but rather increased) the amplitude of the UR with respect to a number of reference points, including between-groups and within-subject comparisons. The additional observation that the inhibitor potentiated the facilitating effect of the conditioned excitor on UR amplitude merely serves to reinforce the dissociation of CR and UR processes suggested by Rescorla's $(1974,1979)$ treatment of conditioning. Specifically, although conditioned inhibitors decreased CRs in the presence of conditioned excitors, they had the opposite effect on the UR.

\section{REFERENCE NOTE}

1. Moore, J. W. Contextual constraints on Pavlovian inhibitory control. In Conditioning context and stimulus control. Symposium presented at the meeting of the American Psychological Association, New Orleans, September 1974.

\section{REFERENCES}

Gormezano, I., \& Moore, J. W. Classical conditioning. In M. H. Marx (Ed.), Learning: Processes. Toronto: Collier-Macmillan, 1969.
Ison, J. R., \& Leonard, D. W. Effect of auditory stimuli on the amplitude of the nictitating membrane reflex of the rabbit (Oryctolagus cuniculus). Journal of Comparative and Physiological Psychology, 1971, 75, 157-164.

KonORSKI, J. Conditioned reflexes and neuron organization. Cambridge: Cambridge University Press, 1948.

Marchant, H. G., III, Mis, F. W., \& Moore, J. W. Conditioned inhibition of the rabbit's nictitating membrane response. Journal of Experimental Psychology, 1972, 95, 408-411.

Marchant, H. G., III, \& Moone, J. W. Below-zero conditioned inhibition of the rabbit's nictating membrane response. Journal of Experimental Psychology, 1974, 102, 350-352.

ReISS, S., \& Wagner, A. R. CS habituation produces a "latent inhibition effect" but no active "conditioned inhibition." Learning and Motivation, 1972, 3, 237-245.

Rescorla, R. A. A model of Pavlovian conditioning. In V. S. Rusinov (Ed.), Mechanisms of formation and inhibition of conditional reflex. Moscow: Academy of Sciences of the U.S.S.R., 1974.

RESCorla, R. A. Conditioned inhibition and extinction. In A. Dickinson \& R. A. Boakes (Eds.), Mechanisms of learning and memory: A memorial volume to Jerzy Konorski. Hillsdale, N.J: Erlbaum, 1979.

Rescorla, R. A., \& Holland, P. C. Associations in Pavlovian conditioned inhibition. Learning and Motivation, 1977, 8, 429-447.

Thomas, E., \& Basbaum, C. Excitatory and inhibitory processes in hypothalamic conditioning in cats: Role of the history of the negative stimulus. Journal of Comparative and Physiological Psychology, 1972, 79, 419-424.

Wagner, A. R., \& Rescorla, R. A. Inhibition in Pavlovian conditioning: Application of a theory. In R. A. Boakes \& M. S. Halliday (Eds.), Inhibition and learning. London: Academic Press, 1972.

Wagner, A. R., Thomas, E., \& Norton, T. Conditioning with electrical stimulation of the motor cortex: Evidence of a possible source of motivation. Journal of Comparative and Physiological Psychology, 1967, 64, 191-199.

(Received for publication June 5, 1979; revision accepted December $18,1979$. 